\title{
AQUALIFE Software: A New Tool for a Standardized Ecological Assessment of Groundwater Dependent Ecosystems
}

\author{
Giovanni Strona ${ }^{1}$, Simone Fattorini ${ }^{2}$, Barbara Fiasca ${ }^{2}$, Tiziana Di Lorenzo ${ }^{3}{ }^{\circ}$, Mattia Di Cicco ${ }^{2}$, \\ Walter Lorenzetti ${ }^{4}$, Francesco Boccacci ${ }^{4}$ and Diana M. P. Galassi ${ }^{2, *(D)}$ \\ 1 Research Centre for Ecological Change, University of Helsinki, P.O. Box 4 FI-00014 Helsinki, Finland; \\ giovanni.strona@helsinki.fi \\ 2 Department of Life, Health and Environmental Sciences, University of L'Aquila, 67100 L'Aquila, Italy; \\ simone.fattorini@univaq.it (S.F.); barbara.fiasca@univaq.it (B.F.); diciccomattiauni@yahoo.it (M.D.C.) \\ 3 Italian National Research Council, Research Institute on Terrestrial Ecosystems, Via Madonna del Piano 10, \\ Sesto Fiorentino, 50019 Florence, Italy; tiziana.dilorenzo@cnr.it \\ 4 Gis3W S.r.l, Viale Verdi 24, Montecatini Terme, 51016 Pistoia, Italy; lorenzetti@gis3w.it (W.L.); \\ boccacci.francesco@gmail.com (F.B.) \\ * Correspondence: dianamariapaola.galassi@univaq.it
}

Received: 30 October 2019; Accepted: 2 December 2019; Published: 6 December 2019

\begin{abstract}
We introduce a suite of software tools aimed at investigating multiple bio-ecological facets of aquatic Groundwater Dependent Ecosystems (GDEs). The suite focuses on: (1) threats posed by pollutants to GDE invertebrates (Ecological Risk, ER); (2) threats posed by hydrological and hydromorphological alterations on the subsurface zone of lotic systems and groundwater-fed springs (Hydrological-Hydromorphological Risk, HHR); and (3) the conservation priority of GDE communities (Groundwater Biodiversity Concern index, GBC). The ER is assessed by comparing tolerance limits of invertebrate species to specific pollutants with the maximum observed concentration of the same pollutants at the target site(s). Comparison is based on an original, comprehensive dataset including the most updated information on tolerance to 116 pollutants for 474 freshwater invertebrate species. The HHR is assessed by accounting for the main direct and indirect effects on both the hyporheic zone of lotic systems and groundwater-fed springs, and by scoring each impact according to the potential effect on subsurface invertebrates. Finally, the GBC index is computed on the basis of the taxonomical composition of a target community, and allows the evaluation of its conservation priority in comparison to others.
\end{abstract}

Keywords: AQUALIFE software; groundwater dependent ecosystems; threats; biodiversity

\section{Introduction}

Groundwater dependent ecosystems (GDEs) are ecosystems whose biological structure and ecological processes are directly or indirectly influenced by groundwater [1,2]. They may include springs, wetlands, streams and rivers, hyporheic zones, lakes, coastal lagoons, and saturated aquifers (also indicated as Subsurface Groundwater Dependent Ecosystems, SGDEs). Aquatic GDEs are known to host a high biodiversity, including highly specialized, rare, and often narrow endemic species [3-5]. Preserving their biodiversity is therefore identified as a conservation priority [5-11]. Many GDEs, and hence their biodiversity, are known to be at risk of impairment worldwide $[4,7,10,12,13]$.

Some regulations for the protection of GDEs have recently entered in force in the Australian subcontinent [14,15] and, to a lesser extent, in Europe [10]. Although these ecosystems are cited in Annex II, Section 2, "Groundwater", pt. 2.2. of the EU Directive 2000/60/EC [16], and later in the 
Directive 2006/118/EC, also called Groundwater Daughter Directive [17], only a few GDEs have been included in Nature 2000 network or designated as Ramsar areas [18,19]. In the United States, a mosaic of laws acts directly or indirectly towards the protection of groundwater and GDEs by controlling contamination, managing conflicts among users, and quantifying abstraction but a comprehensive governance is still missing [20,21]. Proposals for management and recovery of GDEs have been advanced for particular situations, such as mining [12] and groundwater withdrawal [22]. However, current proposals [10] for management actions remain quite vague and protocols to assess the impacts of chemical and hydrological-hydromorphological threats on aquatic GDEs and their conservation priorities are still lacking.

To cope with one of the major challenges of integrating scientific knowledge and environmental management policy, the European Union Life + project "LIFE12 BIO/IT/000231-AQUALIFE" developed a set of procedures and indicators for the assessment of aquatic GDE biodiversity and its threats. The project implemented this set of procedures and indicators into the software suite called "AQUALIFE Software" (hereafter, AS), which we introduce here.

The AS consists of a user-friendly online interface, and it is free to use (after registration) at: http://app.aqualifeproject.eu.

\section{Software Capabilities}

AS allows users to compute a set of different metrics to evaluate the ecological risk, the hydrological-hydromorphological risk, and the conservation priority of aquatic GDEs. The software has been mainly developed using the Python programming language [23] in combination with the Django web framework [24].

The target for the application of the software is, in principle, a set of monitoring sites and their associated biological communities. The software was generated by assembling a rich biodiversity dataset for selected GDEs in the Abruzzo region (Italy), which was chosen as a pilot area for AS development. Users can use their own biodiversity datasets, together with the concentration of the pollutants measured in their sites and, if working on the hyporheic habitat of streams and rivers or groundwater-fed springs, the hydrological-hydromorphological impacts detected in their study sites. All the AS outputs can be saved online, accessed, and downloaded at any later stage.

AS comprises three sections, namely: Ecological Risk (ER), Hydrological-Hydromorphological Risk (HHR), and Conservation Priority Index (GBC). The first two focus on a particular aspect of the GDEs' vulnerability while the last one on the conservation value of GDE biodiversity. Each section includes three subsections. The first subsection, I-Info, provides general information about the rationale of the main section, as well as technical details regarding the associated computation procedures. The second subsection, $\mathrm{R}$-Risk for the first two sections and I-Index for the third section, allows users to perform the analyses. Finally, the third subsection, H-History, allows users to explore and access saved results from previous analyses.

In the following, we provide a detailed description of the different software sections. In doing that, we mainly focus on the technical aspects of computation procedures and on practical aspects of the user experience. Our aim is to provide stakeholders with enough information to start actively using the software in a fully-conscious manner.

\subsection{Section 1: Ecological Risk}

The Ecological Risk (ER) quantifies the probability that chemicals produced by human activity (hereafter referred as "pollutants") harm the health status of a biological community inhabiting an aquatic GDE [5,25-28]. Since chemical pollutants usually occur in mixtures in GDEs, ER is quantified as in Equation (1) [29,30]:

$$
\mathrm{ER}=\mathrm{RQ}_{\text {mix }}=\Sigma \mathrm{RQ}_{i}=\Sigma \frac{\mathrm{MEC}_{i}}{\mathrm{PNEC}_{i}}
$$


where $\mathrm{RQ}_{i}$ is the risk posed by the $i$ th pollutant in the mixture, $\mathrm{MEC}_{i}$ stands for the Measured Environmental Concentration and $\mathrm{PNEC}_{i}$ for the Predicted No-Effect Concentration of the $i$ th pollutant in the mixture. If more environmental concentrations are available for the $i$ th pollutant, $\mathrm{MEC}_{i}$ of Equation (1) is equal to the highest concentration measured by the user, to account for the worst-case scenario [31]. $\mathrm{PNEC}_{i}$ is the concentration at which the $i$ th pollutant is predicted to have no significant detrimental effect on the GDE community [32]. $\mathrm{PNEC}_{i}$ is computed as follows [31]:

$$
\mathrm{PNEC}_{i}=\sqrt[n]{\mathrm{PNEC}_{1} \times \mathrm{PNEC}_{2} \times \ldots \mathrm{PNEC}_{n}}
$$

where

$$
\mathrm{PNEC}_{n}=\frac{\mathrm{LC} 50(\mathrm{EC} 50)}{\mathrm{AF} a}
$$

or

$$
\mathrm{PNEC}_{n}=\frac{\mathrm{NOEC}}{\mathrm{AFb}}
$$

$\mathrm{PNEC}_{i}$ is the geometric mean of $\mathrm{PNEC}_{n}$ where $\mathrm{PNEC}_{n}$ is the predicted no-effect concentration of the $i$ th pollutant on the $n$th taxon of a GDE community represented by $n$ taxa $[31,33,34]$. LC 50 (Lethal Concentration 50\%) and $\mathrm{EC}_{50}$ (Effect Concentration 50\%) are the concentrations of the $i$ th pollutant producing, respectively, a lethal effect or a maximal effect, on $50 \%$ of individuals tested in short-term trials $(\leq 96 \mathrm{~h}$ ) and NOEC (No-Observed Effect Concentration) is the concentration producing no significant effects under long-term exposures $(>96 \mathrm{~h})$. AF is an assessment factor that reflects the uncertainty in extrapolating $\mathrm{PNEC}_{n}$ values from laboratory toxicity tests [27], being AFa equal to 1000 and $\mathrm{AF} b$ equal to $100[35,36]$. If more than one $\mathrm{LC}_{50}$ and/or $\mathrm{EC}_{50}$ and/or NOEC values are available for the $n$th taxon, the toxicity data are aggregated by computing their geometric mean [31].

AS provides an internal database of PNECs for 116 pollutants known to be potential threats to GDEs; they were derived from 8806 toxicity values related to 474 taxa either found in GDEs or in other freshwater habitats according to information availability (Tables S1 and S2). Toxicity data were retrieved from the US EPA database ECOTOX "Aquatic Data" [37]. When unavailable, LC $_{50}$ values were estimated by US EPA ECOSAR v.2.0 [38]. We used the most updated literature to amend errors (for example, wrong habitat attribution of the records, wrong attribution of the species to the freshwater environment, and wrong species names) as well as to expand the AS database with additional information (e.g., new toxicity data for freshwater species).

In freshwater studies, it is common to focus on tolerance limits of algae, macrophytes, invertebrates, and small fish; however, to assemble the dataset used by AS, we focused only on invertebrates. The rationale behind this choice stems from the circumstantial evidence that in aquatic GDEs there is virtually no primary productivity (except for rare cases of chemoautotrophy [39]) and, as for Europe, no underground fish are known.

AS assigns a risk magnitude and a color to ER based on five classes (Table 1), following the assumption that, if $\mathrm{RQ}_{\text {mix }}>1$, an ER is expected [27,28].

Table 1. ER rating, magnitude and color per rank.

\begin{tabular}{ccc}
\hline ER Rating & ER Magnitude & ER Color Ranking \\
\hline $0 \leq \mathrm{RQ}_{\text {mix }}<1$ & no risk & \\
$1 \leq \mathrm{RQ}_{\text {mix }}<10$ & low risk & \\
$10 \leq \mathrm{RQ}_{\text {mix }}<100$ & medium risk & \\
$100 \leq \mathrm{RQ}_{\text {mix }}<1000$ & high risk & \\
$\mathrm{RQ}_{\text {mix }} \geq 1000$ & very high risk & \\
\hline
\end{tabular}

Because of the dominance of the crustaceans in certain GDEs (e.g., SGDEs), AS allows users to select one out of two subsets of the toxicity database: (i) "crustacean species" (choice suggested for SGDEs such as the saturated aquifers where crustaceans are the dominant group); or (ii) "freshwater 
invertebrates" (choice suggested for springs and the hyporheic zone of streams and rivers, where also non-crustacean species are present, and often with high abundances).

The computation of $R_{Q_{m i x}}$ by $A S$ is straightforward. After loading the Ecological Risk page, the user can select the pollutants from a drop-down list, enter the MECs for the pollutants detected in the GDE sites under study, select one out the two subsets of toxicity database, and start the calculation of $\mathrm{RQ}_{\text {mix }}$ by pressing the "RUN" button. After that, AS will provide the user with both the individual PNEC values of the selected pollutants, and the $R_{Q_{\text {mix }}}$ value along with the ER magnitude and color.

AS allows the user to save the analyses and access them at a later moment. To do this, the user will have to associate the analysis to a geographical location (either a location indicated in previous analyses or a new one; in the latter case, the user will have to assign an arbitrary name to the locality and will have the possibility to provide its geographical coordinates, in form of latitudinal/longitudinal decimal degrees). An interactive map will show the position of the target site(s). After that, a "SAVE" button will become available. The last step consists in attributing an identifier name to the analysis, allowing its later retrieval. Saved analyses are accessible by the user in the History Page of the Ecological Risk section. Clearly, users have personalized histories, and do not have access to other user pages. Data from the History subsection can be directly exported to spreadsheet documents for being processed outside the software environment.

\subsection{Section 2: Hydrological-Hydromorphological Risk}

The second section of AS aims at identifying and scoring potential risks posed by man-induced alterations of the hydrological connectivity (Hydrological-Hydromorphological Risk, HHR) of specific GDE types such as hyporheic zones of streams and rivers and groundwater-fed springs. We designed our procedure taking as a model the Index of Morphological Quality and the Morphological Alteration Index, two operational tools of the Italian "Hydromorphological evaluation system, analysis and monitoring of rivers" named IDRAIM [40].

Several factors can potentially alter the hydrological connectivity of the subsurface habitats from surface waters as well as from the underlying aquifer [41,42], critically influencing hyporheic invertebrate communities [43-45]. Among them, important ones are alteration of streamflow dynamics, changes in streambed and river banks structure and morphology, and reduction of streambed sediments heterogeneity (i.e., colmation or clogging [46]), mainly arising from the presence of dams [42,47-49], barriers, water derivation works, and groundwater overexploitation [21] (HHYC = altered habitat due to hydrological changes [50]).

The presence of solid walls and/or embankments limiting permeability with the alluvial plain of streams and rivers, concreted riverbed, presence of knick points in rivers, artificial riverbed aggradation, channelization [51], clogging or colmation [52-54], artificial elevation of the riverbed, and removal of perifluvial vegetation $[55,56]$ may lead to an alteration of the vertical connectivity river/aquifer $[48,57]$ (HMOC $=$ altered habitats due to morphological changes [50]).

Concerning groundwater-fed springs, alteration of the discharge in the eucrenal-hypocrenal of the spring environment, and in the epirhytron (mountain streams) and alteration of the spring morphology affect severely the crenocenosis and may also cause a disconnection between the spring and the stream $[58,59]$. If the aquifer feeding the spring is overexploited, an alteration of the spring discharge is expected [58,60-62]. Spring casing and/or concretion (piping, impoundment, and diversion of spring flows), removal of riparian vegetation [63] for maintenance works are reflected in HMOC impacts, such as alteration of the spring morphology with interruption of the spring/aquifer and spring/stream connections, habitat losses, and changes in the nutrient dynamics after vegetation removal [64].

The computation of the HHR is based on the pressures generating effective impacts on GDE invertebrate faunas, with a distinction between those insisting on the hyporheic zones (Table 2) and those affecting springs (Table 3). The list of pressures has been compiled based on expert judgment and is available in the INFO subsection of the main menu under the heading "Hydrological-Hydromorphological Risk" (Tables 2 and 3), which includes a description of the pressures 
and the indication of the impacts, along with the relative category (i.e., impacts altering habitats due to hydrological changes (HHYC) and impacts altering habitats due to morphological changes $(\mathrm{HMOC})$ ) [50]. A cutoff of 10 ("at risk" vs. "no risk") was identified as the threshold value of the overall impact, which corresponds to the maximum partial impact score attributed to the alteration of the river/aquifer connection exerted by different pressures, considering this alteration sufficient to produce the disappearance of a GDE. All the scores assigned to each impact are stored into the AS.

Table 2. Relevant pressures and related impacts for hyporheic habitats. Pressures and impacts are as so in the Guidance No. 35 of the Water Framework Directive Reporting Guidance 2016, Annexes $1 \mathrm{~b}$ and $8 \mathrm{n}[50]$.

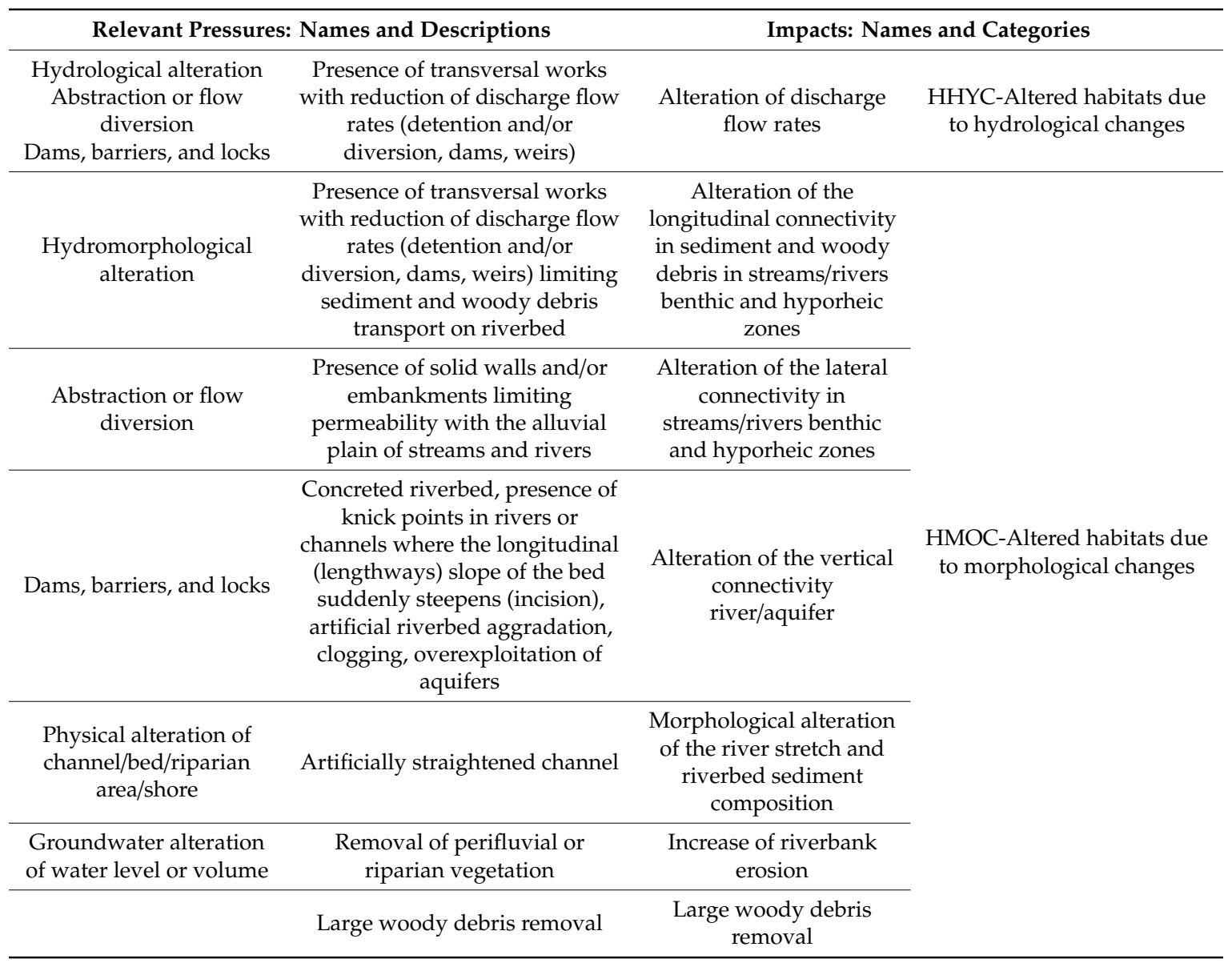

For hyporheic habitats, most of the pressures are to be evaluated in a river stretch of at least $100 \mathrm{~m}$ upstream of the target site. As the effects of dams or river derivations can occur several tens of kilometers downstream, the user will assess their effectiveness at the target site.

A similar set of criteria was adopted to assess the HHR for groundwater-fed springs, where the main pressures are represented by hydrological alteration due to abstraction or flow diversion, dams, or barriers downstream from the spring, which may determine HHYC and HMOC impacts (Table 3 and Table 5).

A score was assigned to each impact based on expert judgment, considering the deviation from reference conditions of unmodified rivers or spring systems. Therefore, the score reflects the degree of alteration of a GDE site related to a given pressure (Tables 4 and 5). 
Table 3. Relevant pressures and related impacts for groundwater-fed springs are as so in the Guidance No. 35 of the Water Framework Directive Reporting Guidance 2016, Annexes 1b and 8n [50].

\begin{tabular}{|c|c|c|c|}
\hline \multicolumn{2}{|c|}{ Relevant Pressures } & \multicolumn{2}{|c|}{ Impacts } \\
\hline \multirow[t]{2}{*}{$\begin{array}{l}\text { Hydrological alteration } \\
\text { Abstraction or flow } \\
\text { diversion } \\
\text { Dams, barriers, and locks }\end{array}$} & $\begin{array}{l}\text { Presence of transversal works } \\
\text { with reduction of discharge flow } \\
\text { rates (detention and/or } \\
\text { diversion, dams, weirs) } \\
\text { downstream the spring } \\
\text { emergence }\end{array}$ & $\begin{array}{c}\text { Alteration of discharge flow } \\
\text { rate }\end{array}$ & $\begin{array}{l}\text { HHYC-Altered habitats due } \\
\text { to hydrological changes }\end{array}$ \\
\hline & Overexploitation of aquifers & $\begin{array}{l}\text { Alteration of the vertical } \\
\text { connectivity }\end{array}$ & \\
\hline \multirow[t]{2}{*}{$\begin{array}{l}\text { Physical alteration of } \\
\text { channel/bed/riparian } \\
\text { area/shore }\end{array}$} & $\begin{array}{l}\text { Spring used for different } \\
\text { purposes or concreted at its } \\
\text { emergence }\end{array}$ & $\begin{array}{l}\text { Morphological alteration of } \\
\text { spring habitats with loss of } \\
\text { the ecotonal nature of } \\
\text { GW-fed springs }\end{array}$ & $\begin{array}{l}\text { HMOC-Altered habitats due } \\
\text { to morphological changes }\end{array}$ \\
\hline & Riparian vegetation removal & $\begin{array}{l}\text { Habitat and microhabitat } \\
\text { losses, nutrient dynamics } \\
\text { alteration, current velocity } \\
\text { alteration }\end{array}$ & \\
\hline
\end{tabular}

Table 4. Impact scores for hyporheic habitats.

\begin{tabular}{cc}
\hline Impacts & Impact Score \\
\hline Alteration of discharge flow rates & 6 \\
Alteration of the longitudinal connectivity limiting sediment and woody debris & 4 \\
transport on riverbed & 3 \\
Alteration of the lateral connectivity & 10 \\
Alteration of the vertical connectivity river/aquifer & 6 \\
Alteration of riparian vegetation & 2 \\
Lowering of woody debris storage in streams/rivers & 1 \\
\hline
\end{tabular}

Table 5. Impact scores for groundwater-fed springs.

\begin{tabular}{|c|c|}
\hline Impacts & Impact Score \\
\hline Alteration of discharge flow rates & 6 \\
\hline $\begin{array}{l}\text { Alteration of the ecological features of the spring (e.g., change from rheocrenic to } \\
\text { limnocrenic spring as effect of damming) }\end{array}$ & 4 \\
\hline Alteration of the vertical connectivity & 10 \\
\hline $\begin{array}{l}\text { Morphological alteration of spring habitats with loss of the ecotonal nature of } \\
\text { GW-fed springs }\end{array}$ & 5 \\
\hline $\begin{array}{c}\text { Alteration of the riparian vegetation, habitat and microhabitat losses, nutrient } \\
\text { dynamics alteration, current velocity alteration }\end{array}$ & 3 \\
\hline
\end{tabular}

The computation of HHR is performed by AS in two simple steps. In the first step, users are asked to select the target habitat (either hyporheic or spring habitats).

Depending on this first selection, a pre-defined list of pressures and impacts becomes available, that is either Table 2 or Table 3. The second step consists in choosing from this list the impact(s) recorded at the target site (Table 4 or Table 5). After that, the "RUN" button leads the user to the results window, which provides a risk score (Table 6), and a summary of the user selections.

Table 6. HHR rating, risk ranking, and color per rank.

\begin{tabular}{ccc}
\hline HHR Rating & Risk Ranking & HHR Color Ranking \\
\hline HHR $<10$ & no risk & \\
HHR $\geq 10$ & at risk & \\
\hline
\end{tabular}


As for ER, results can be associated with a geographic location and stored in an internal database that the user can access at any moment through the "History" subsection.

\subsection{Section 3: Conservation Priority Index}

The third section of AS allows the computation of three conservation indices: Sum of Species Scores (SSS), Biodiversity Conservation Concern (BCC), and Groundwater Biodiversity Concern (GBC). These indices aim at prioritizing GDE communities on the basis of their conservation importance. Although species richness is an obvious criterion to select conservation priority areas, not all species have the same conservation importance. For example, areas that host more imperiled species should be considered more important $[65,66]$. However, estimating species extinction risk may be extremely difficult, especially for less known invertebrates [67]. For this reason, there is increasing interest in the use of rarity measures as a proxy for the extinction risk of invertebrates [68-70]. Rarity is a relative and multidimensional concept, because a species can be more or less rare compared to other species for various characteristics [71-73]. Once the rarity of a species has been assessed for the various dimensions that are considered, this information can be used to obtain scores that express the overall species' conservation priority. Under these assumptions, AS uses a two-step protocol to assess the conservation priority of GDEs based on invertebrate species. The first step consists in computing the conservation priority of each species occurring in GDE sites based on selected species traits. The second step is to compute site conservation indices using species scores.

The computation of the indices requires users to fill and upload: (1) a dataset where each species (but other taxonomic units can be used) is associated with a set of traits that expresses its conservation importance (the "Dataset" file must contain species in rows, traits in columns); and (2) a matrix of each species abundance across the compared sites (if abundance data are not available, presence/absence can be used) (the "Sampling" file must contain species in rows and sites in columns). Both need to be provided to AS as spreadsheets (.xls). By processing these two input files, AS will compute both a conservation score for each species in the dataset, and three conservation indices for each site (with different scores of the GBC index being associated with different conservation priority categories).

Trait scores are attributed by the user to the collected species for five dimensions (geography, ecology, biology, population, and evolutionary history), each divided into different traits (Table 7). For each trait, the higher is the score, the higher is the species' conservation importance. Different traits have different score ranges. For example, in the "Geography" dimension, the trait "Degree of Endemicity" can obtain a score from 1 to 4 , while the trait "Extent of occurrence" can obtain a score from 1 to 7 [74].

Table 7. Traits and their scores used to calculate the Conservation Priority Index.

\begin{tabular}{ccc}
\hline Dimension & Trait & Score Range \\
\hline 1. GEOGRAPHY & Extent of occurrence & $1-7$ \\
& Degree of endemicity & $1-4$ \\
\hline 2. ECOLOGY & Degree of GW dependence & $1-5$ \\
& Ecological specialization to GW & $1-3$ \\
& Size of ecological niche & $1-5$ \\
& Tolerance to variation of climatic parameters & $1-5$ \\
& Microhabitat preferences & $1-5$ \\
\hline 3. BIOLOGY & Trophic role & $1-5$ \\
& Life time span & $1-3$ \\
\hline 4. POPULATION & Frequency & $1-4$ \\
& Abundance & $1-4$ \\
\hline 5. EVOLUTIONARY HISTORY & Evolutionary origin & $1-3$ \\
& Phylogenetic rarity & $1-5$ \\
\hline
\end{tabular}


Except for "Frequency" and "Abundance", which are calculated by AS, scores for the other traits are assigned to each species present in the dataset by the user on the basis of the best available information. Thus, these scores are based on expert judgment. Frequency and Abundance scores are calculated by AS using site data because these traits are not species-specific, but site-specific (the same species may show different population characteristics at different sites). "Frequency" is given by AS calculating first the frequency of occurrence of each species across the total number of studied sites, and then by attributing to each species a score (from 1 to 4 ) based on quartiles (with score 1 assigned to species falling above the third quartile, which are the most widely distributed species, and score 4 assigned to species with frequency below the first quartile, which are the species with the narrowest distribution). The "Abundance" trait is computed by AS in a similar way: relative abundance is computed for all species, and then to each species is attributed a score (from 1 to 4 ) based on quartiles. If abundance data are not available, and only presence/absence data are used, this trait is automatically excluded from calculations.

Trait scores (assigned to each species by the user) belonging to the same dimension are multiplied by AS to obtain a synthetic score for each dimension. Once this operation has been made for all the species in the dataset, a distribution of synthetic scores becomes available for each dimension. These synthetic scores have different ranges. For example, the score for Dimension 1 (Geography) may vary between 1 and 28 (for a species that ranked highest for the two traits included in this dimension), while the score for Dimension 2 (Ecology) may vary between 1 and 1875 (for a species that obtained the maximum score for each of the five traits included in this dimension). For this reason, scores resulting from multiplications are divided using quartiles, and values falling within the same interquartile range receive the same score, ranging from 1 (values below the first quartile) to 4 (values above the third quartile). The use of quartiles to rescale original products into four classes with integer values (i.e., 1, 2, 3 , and 4) was adopted in AS to make dimensions comparable. After the quartilization of products, the new scores are summed up to obtain the overall species score. This sum of scores (which can theoretically range from 5 , for a species which scored 1 for all five dimensions, to 20, for a species which scored 4 for all dimensions) is rescaled to vary between 1 and 4 by simply dividing by 5 . In this way, each species receives a score represented by a value varying between 1 and 4 (SS, Species Scores).

AS generates and uses the SS scores to compute three distinct site-specific indices, and particularly:

(1) Sum of Species Scores (SSS) normalized between 0 and 1 using the formula (Equation (5)):

$$
\text { SSSrescaled }=\left(\mathrm{SSS}-\mathrm{SSS}_{\min }\right) /\left(\mathrm{SSS}_{\max }-\mathrm{SSS}_{\min }\right)
$$

with SSS $_{\min }$ and SSS $_{\max }$ being, respectively, the minimum and maximum SSS scores recorded across all studied sites.

(2) Biodiversity Conservation Concern (also varying between 0 and 1) (Equation (6)):

$$
\mathrm{BCC}=(\mathrm{SSS} / \mathrm{N}-1) /\left(\mathrm{SS}_{\max }-1\right)
$$

where $\mathrm{N}$ is the total number of species present in a site and $\mathrm{SS}_{\max }$ is the maximum value of the $\mathrm{SS}$ values.

(3) Groundwater Biodiversity Concern (GBC) computed as the mean of SSSrescaled and BCC. GBC values are finally used to identify different priority classes (Table 8).

Table 8. GBC rating, priority ranking and color per rank.

\begin{tabular}{ccc}
\hline GBC Rating & Priority Ranking & GBC Color Ranking \\
\hline $0 \leq \mathrm{GBC} \leq 0.2$ & very low priority & \\
$0.2<\mathrm{GBC} \leq 0.4$ & low priority & \\
$0.4<\mathrm{GBC} \leq 0.6$ & medium priority & \\
$0.6<\mathrm{GBC} \leq 0.8$ & high priority & \\
$0.8<\mathrm{GBC} \leq 1$ & very high priority & \\
\hline
\end{tabular}


After uploading the files including the table of species scores for each trait, and the matrix of species occurrences/abundances, by pressing the "RUN" button users will be prompted to the results page, which will include both the individual species scores of all species included in the analysis, as well as the site-specific scores, including the raw and rescaled SSS, the BCC, and the GBC (together with the corresponding conservation priority class).

As for the previous sections, users can save all their results, access them at any moment, and export them for additional analysis outside the AS.

\section{Example of Application: The Hyporheic Zone of the River Sagittario}

To understand the main outputs of AS, namely ER, HHR, and GBC, six hyporheic sites (ABRO86/3S, ABRO87/3S, ABRO88/3S, ABRO89/3S, ABRO90/3S, and ABRO91/3S; Figure 1) of the River Sagittario (Italy) were selected from the AQUALIFE network of sites (Tables S3-S5). The River Sagittario in the Sulmona plain is among the most altered rivers in central Italy [75], thus representing a model environmental system for assessing the effects of different types of pressures on hyporheic biodiversity. At each site, we performed two temporal surveys, namely in December 2014 (winter) and in June 2015 (summer). Hyporheic samples were collected pumping $10 \mathrm{~L}$ of interstitial water by a membrane pump connected to steel pipes screened at $-40 \mathrm{~cm}$ deep and filtered through a $60 \mu \mathrm{m}$ hand net. Faunal samples were preserved in a 70\% alcohol solution. In the laboratory, specimens were sorted under a stereomicroscope at $16 \times$ magnification and identified to the lowest taxonomic level possible using a LEICA M205C stereomicroscope. Based on the human activities carried out in the catchment of the River Sagittario, 108 chemicals (including N-compounds, phosphates, metals, volatile organic compounds, and pesticides) were analyzed per each sample taking a $2 \mathrm{~L}$ volume. The concentrations of most chemicals (101 out of 108) were below the limit of detection. The MECs of the seven chemical compounds out of 108 (namely, nitrites, nitrates, sulfates, chloride, phosphates, ammonium, and $\alpha \mathrm{HCH}$ ) exceeding the limits of detection are reported in Table S3. The hydrological-hydromorphological impacts affecting the GDE sites are reported in Table S4. Overall, 58 invertebrate taxa were identified (Table S5) and the trait scores, used by AS to calculate the GBC index, were assigned (Table S5). The invertebrate assemblages were mostly composed by stygobionts or species highly dependent on groundwater (Table S5; see the column "Ecological specialization to GW"). AS was run for each site and the results are summarized in Table 9 and Figure 1. The ER outputs revealed that all sites were at medium risk along the whole river sector (Table 9). No hydrological-hydromorphological risk was reported for the upstream sites ABRO86/3S and ABRO87/3S $(\mathrm{HHR}<10)$ while the four remaining downstream sites showed an HHR $>10$ (Table 9). Finally, the highest GBC value $(\mathrm{GBC}=0.667)$ was reached in $A B R O 86 / 3 S$ where medium $E R\left(R Q_{m i x}=58.85\right)$ and $H H R=6$ (no risk) were calculated by AS. In the remaining sites the GBC was in the range very low-medium. The lowest GBC $(G B C=0.172)$ was assigned by AS to the site $A B R O 89 / 3 S$ with low species richness, medium $E R\left(R_{\text {mix }}=72.10\right)$, and HHR $=13$ (at risk) (Table 9 and Figure 1). The application of AS to the River Sagittario has highlighted that the hyporheic zone has only one site with a significant conservation importance. The GDE assemblages experience a medium risk due to pollution of a limited number of substances in all sites, while the hydrological-hydromorphological alteration of the GDE sites under study occurs only in the most downstream sites. This scenario requires management choices that are discussed in detail in the next paragraph. 


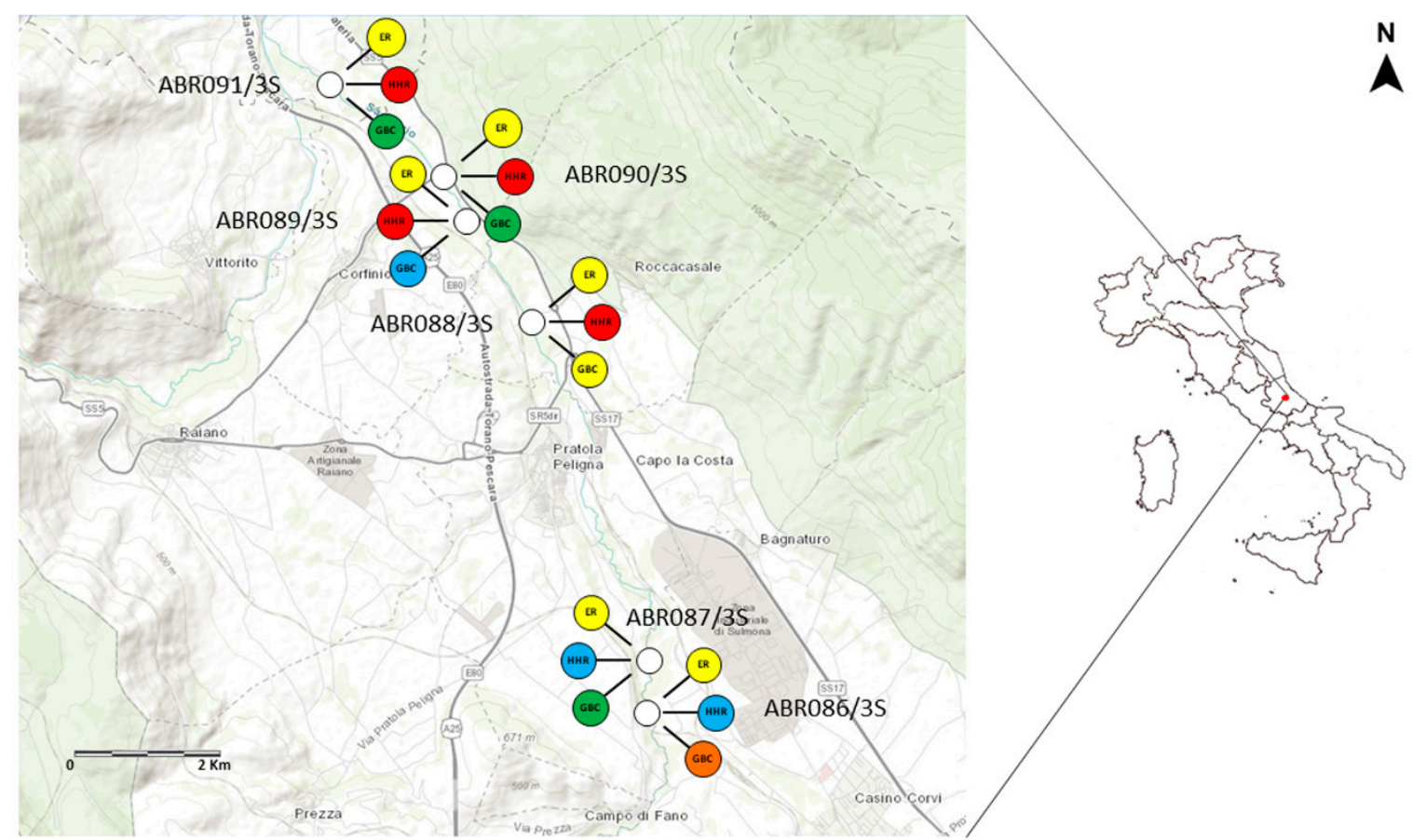

Figure 1. Sampling sites (white circles) of the hyporheic zone of the River Sagittario. Color-coded circles are used to indicate the ranks of the ecological risk (ER), the hydrological-hydromorphological risk (HHR), and the groundwater biodiversity concern index (GBC).

Table 9. AS outputs for ER (Environmental Risk), HHR (Hydrological-Hydromorphological Risk) and the conservation priority indices (SSS, Sum of Species Scores; SSS rescaled, Sum of Species Scores rescaled; BCC, Biodiversity Conservation Concern; GBC, Groundwater Biodiversity Concern) for the example of application in the hyporheic zone of the River Sagittario (Italy).

\begin{tabular}{cccccccccc}
\hline $\begin{array}{c}\text { Sampling } \\
\text { Site }\end{array}$ & $\begin{array}{c}\text { ER } \\
\mathbf{( R Q}_{\text {mix }} \mathbf{)}\end{array}$ & $\begin{array}{c}\text { ER } \\
\text { Ranking }\end{array}$ & HHR & $\begin{array}{c}\text { HHR } \\
\text { Ranking }\end{array}$ & SSS & $\begin{array}{c}\text { SSS } \\
\text { Rescaled }\end{array}$ & BCC & GBC & $\begin{array}{c}\text { Priority } \\
\text { Ranking }\end{array}$ \\
\hline ABRO86/3S & 58.85 & medium & 6 & no risk & 16 & 1 & 0.333 & 0.667 & high \\
ABRO87/3S & 83.75 & medium & 6 & no risk & 13.8 & 0.421 & 0.324 & 0.372 & low \\
ABRO88/3S & 32.11 & medium & 28 & at risk & 15 & 0.737 & 0.381 & 0.559 & medium \\
ABRO89/3S & 72.10 & medium & 20 & at risk & 12.2 & 0 & 0.344 & 0.172 & very low \\
ABRO90/3S & 51.22 & medium & 16 & at risk & 13.6 & 0.368 & 0.314 & 0.341 & low \\
ABRO91/3S & 49.05 & medium & 15 & at risk & 13.8 & 0.421 & 0.324 & 0.372 & low \\
\hline
\end{tabular}

\section{Discussion}

The introduction of the concept of GDE in the context of the Water Framework Directive and the subsequent issuing of specific guidelines have certainly represented a considerable advancement in the protection of aquatic and, in particular, groundwater dependent ecosystems [10]. Due to their communicative effectiveness, scores and color-coded maps have been strongly recommended by legislations worldwide to illustrate the ecological status, the risk, and the monitoring network of water bodies [16]. In fact, scores and colors are intuitive and of immediate understanding even for non-experts and have the advantage of making people aware of information that has been long confined to technicians.

AS provides a user-friendly toolkit to assess (i) the risk effectively or potentially posed to the GDE communities by chemical pollutants; (ii) the hydrological-hydromorphological risk (available for ecotonal GDEs, such as hyporheic zones and groundwater-fed springs); and (iii) the conservation priority of GDE sites based on the community composition. Due to its structure and, above all, thanks to 
the outputs that are given in scores and color-coded maps, AS fully meets the requirements of intuitive communication of the legislations.

In AS, each index may work either alone or in conjunction with the others, without the limitations of single-function applications. AS creatively addresses also a risk scale for the ecological risk, based on the $\mathrm{RQ}_{\text {mix }}$ rating, thus allowing the user to measure how far each site is from the condition of "no risk". This graded scale of risk, even if not provided for by any international regulation, allows the user to make an informed choice on which sites require priority recovery and which do not. ER has more classes (five) than HHR (two). This is due to the higher level of knowledge that is available for the ecological risk compared to the hydrological-hydromorphological risk for which scoring is available only for surface water bodies, thus preventing a fine-tuning of the HHR scoring for the GDEs. On a regulatory basis, water bodies are still divided in at risk vs. not at risk, but a further division in classes of the ecological risk is possible ([27] and references therein).

The major advantage of the software is that of providing integrated information. The integration of the most commonly assessed ecological risk with the hydrological-hydromorphological risk is certainly a key-point of AS. In fact, through the HHR index, it is immediately evident to the user that chemical pollution is not always the main factor of GDE degradation. In fact, the greatest impact on GDEs is often due to human activities such as river bed reshaping, grinding, bank defenses, embankments, coatings, burial, vegetation cutting, etc. The attention paid by AS to the physical components of GDEs makes it possible to broaden the horizon of the management measures of protection and recovery [56]. We recommend computing ER along with HHR, because hydrological and hydromorphological impacts occurring in the river channels or groundwater-fed springs can lead to an increasing pollutant concentration both in the hyporheic zone or in spring water and in the feeding aquifers. For instance, areas with intensive agriculture, where a massive riparian vegetation removal has been practiced along river banks, are characterized by higher concentrations of nitrates and ammonium, mainly in the hyporheic zone [26,76] and in the SGDEs, i.e., the saturated aquifers [31,76,77]. The third tool of AS allows the assessment of the conservation priority of sites on the basis of the uniqueness of the species collected in aquatic GDE (and SGDE) sites. This set of indicators (SSS, BBC, and GBC) may work in combination with ER and HHR, based on the assumption that the higher the ER and HHR scores, the higher the risk of biodiversity loss, especially for the most sensitive species. This assumption is not necessarily true, since many variables come into play to define whether a given site is permanently disturbed or not. Furthermore, individual sites are often interconnected, for example if they belong to the same aquifer, or to the hyporheic zone of the same river, thus ensuring a recolonization of perturbed sites from unpolluted aquifer sectors or hyporheic stretches [78].

AS can support European Member States in the preparation of the GDE management plans under the EU Directive 2000/60/EC [16]. Every six years (duration of a management plan) all Member States must indicate the GDEs at risk or not at risk and the related management measures. The actions concern: (i) a new census of anthropic pressures; (ii) a monitoring program, which can be distinguished in surveillance monitoring (which applies exclusively to not-at-risk GDEs) and operational monitoring (which applies to at-risk GDEs); and (iii) protection measures involving interdictions of impactful human activities in the entire GDE or part of it. The list of pressures must be updated every six years, regardless of the risk conditions of the GDE. The choice between the types of monitoring programs has profound economic impact. Surveillance monitoring is largely sustainable because it can be performed only in one point of a given GDE, on basic physico-chemical (e.g., pH, electrical conductivity, and nitrates) and hydrological-hydromorphological parameters (e.g., flow rate, water level, damming, etc.) and with a frequency of one time every six years. On the other hand, the operational monitoring is much more expensive because it involves a significant number of sites and parameters and a frequency of at least once a year for the entire duration of the management plan. In addition, protection measures are often required in at-risk GDEs. To facilitate decision-makers in the choice of the type of monitoring program, we propose to refer to the individual values of the indicators, as shown in Table 10, where ER and HHR provide indications for the type of monitoring and GBC for 
the protection measures. Based on this rationale, if ER and HHR indicate that the GDE site is not at risk, the monitoring must be based on surveillance pursuant to the EU Directive 2000/60/EC [16] and no protective action is required regardless of the conservation value of the GDE. If, instead, ER and HHR indicate that the GDE is at risk, the monitoring must always be operational, both for the chemical and hydrological-hydromorphological parameters, but the protection actions may be necessary only at certain risk values. For example, protection measures are not necessary if GBC $=0.7$ (High Priority) and $\mathrm{ER}=9$ and $\mathrm{HHR}<10$. The cases in which AS shows its full utility is when ER does not indicate risk but HHR does (or vice versa). In this case, the monitoring must be operational only for the chemical (or hydrological-hydrogeological) parameters, with a relative cost containment. The study case of the hyporheic zone of the River Sagittario allowed the application of the ER and the HHR together with the GBC (Figure 1). Based on the obtained results, the River Sagittario basin management plan should take into account primarily the restoration of the connectivity between river flowing waters and the underlying aquifer via the hyporheic zone to preserve benthic and hyporheic fauna and the ecosystems services they provide. Four sites out of six were at hydrological-hydromorphological risk for the presence of a dam, water diversion for agriculture, presence of solid walls and/or embankments limiting permeability with the alluvial plain, channelization, artificially straightened channel, and artificial elevation of the riverbed. According to Table 10, the monitoring of the chemical-physical parameters should be operational in all sampling sites while that of the hydrological-hydromorphological variables should be operational in four sites out of six, being based on surveillance in the remaining two sites. Finally, the GBC index indicated that protection measures are required for just one site out of six, namely ABRO86/3S.

Table 10. Decision-making table. Surveillance (SMPs) and operational monitoring program (OMPs) and protection measures (PMs) are indicated according to the values of ER, HHR and GBC indices.

\begin{tabular}{cccccc}
\hline ER Values & $\begin{array}{c}\text { ER } \\
\text { Monitoring } \\
\text { Measures }\end{array}$ & HHR Values & $\begin{array}{c}\text { HHR } \\
\text { Monitoring } \\
\text { Measures }\end{array}$ & GBC Values & Measures \\
\hline $0 \leq \mathrm{RQ}_{\text {mix }}<1$ & SMPs & $\mathrm{HHR}<10$ & SMPs & $0 \leq \mathrm{GBC} \leq 0.2$ & No PMs \\
\hline $1 \leq \mathrm{RQ}_{\text {mix }}<10$ & OMPs & $\mathrm{HHR} \geq 10$ & OMPs & $0.2<\mathrm{GBC} \leq 0.4$ & $\begin{array}{c}\mathrm{PMs} \text { if } \mathrm{RQ} \geq 1000 \\
\text { and } \mathrm{HHR} \geq 10\end{array}$ \\
\hline $10 \leq \mathrm{RQ}_{\text {mix }}<100$ & OMPs & & $0.4<\mathrm{GBC} \leq 0.6$ & $\begin{array}{c}\mathrm{PMs} \text { if } \mathrm{RQ}>100 \\
\text { and } \mathrm{HHR} \geq 10\end{array}$ \\
\hline $100 \leq \mathrm{RQ}_{\text {mix }}<1000$ & OMPs & & $0.6<\mathrm{GBC} \leq 0.8$ & $\begin{array}{c}\mathrm{PMs} \text { if } \mathrm{RQ}>10 \text { and } \\
\mathrm{HHR} \geq 10\end{array}$ \\
\hline $\mathrm{RQ}_{\text {mix }} \geq 1000$ & OMPs & & $0.8<\mathrm{GBC} \leq 1$ & $\begin{array}{c}\mathrm{PMs} \text { if } \mathrm{RQ}>1 \\
\text { and } / \text { or HHR } \geq 10\end{array}$ \\
\hline
\end{tabular}

From the 2000s until today, other valid tools for assessing the ecological and environmental health in GDEs (but not their conservation values) were presented. For instance, the GW-Fauna-Index [79] was the first attempt to classify GDEs (hyporheic zones and alluvial aquifers) in terms of ecologically relevant conditions using factors which best correlated with stygofauna, namely detritus, temperature, and dissolved oxygen. In 2019, an approach based on three microbiological parameters (prokaryotic cell density, prokaryotic intracellular ATP concentrations, and assimilable organic carbon) was proposed as an integration of the existing routine of GDE monitoring [80]. A single index value obtained from multivariate analyses of the microbial parameters proved to best discriminate between disturbed (organic contamination with hydrocarbons, surface water intrusion, and agricultural activities) and undisturbed alluvial aquifers [80]. A more structured and comprehensive framework for measuring GDE health is the Groundwater Health Index (GHI) [81,82] that was presented in 2011 and successively refined in 2017. Relying upon a combination of microbial, stygofaunal, water chemistry, and environmental indicators, GHI can discriminate three distinct ecosystem health classifications, namely "similar to reference", "mild deviation from reference", and "major deviation from reference". 
Other tools were presented to preserve biodiversity of GDEs based on their conservation value (but not on their quality status). A conservation strategy to minimize the risk of groundwater biodiversity loss due to human activities in European GDEs was proposed by designing a network of reserve areas that collectively include most groundwater species [8]. Three area selection methods (species richness hotspots, endemism hotspots, and complementarity) were proposed to preserve 1059 groundwater species of hyporheic zones, springs, and alluvial and karst aquifers in six European regions. Compared to the aforementioned tools, AS offers high flexibility, and can be used, depending on the user needs, in different GDEs and at different spatial scales. In addition, AS is the only available tool that calculates the chemical and hydrological-hydromorphological risks faced by GDEs along with their conservation priority.

However, along with the merits, AS faces also some methodological limitations such as those related, for example, to the number of pollutants for which AS provides the PNECs. Emerging contaminants, such as pharmaceutical compounds, are not represented in the internal database. The HHR index is currently applicable only to ecotonal GDEs, such as hyporheic zones and springs. A HHR for the aquifers (that takes into account quarries, for example, waste materials from stone processing, and the widespread phenomenon of fracking) is still missing. Finally, the scores assigned to each impact are based on expert judgment, which will be potentially tuned with the advancement of knowledge on the GDE functioning and the relative impacts. For this reason, AS will likely be useful for the authorities in charge of GDE management; however, the version presented here should be considered a preliminary workbench toward an appealing refinement of the software itself.

\section{Conclusions}

The purpose of this paper is to present the AQUALIFE software, which is the main product of the AQUALIFE project. AS consists of a user-friendly online interface, and is free to use (after registration) at: http://app.aqualifeproject.eu. AS is a relatively fast, economical tool of investigation that can be used by operators with basic knowledge of aquatic ecosystems dependent on groundwater and that, through training courses, can complete their knowledge and acquire the necessary experience. AS allows the user to assess the conservation priority of GDEs based on species conservation importance along with chemical and hydrological-hydromorphological risks. Thanks to its novelty, AS has the potential to become a user-friendly standard tool not only for researchers, but also for practitioners and decision makers. The scientific awareness of the existence of a unique biodiversity in the GDEs (and SGDEs) and the role it plays in terms of ecosystem services has not had any impact on the perception and cognition of this reality at the regulatory level; in this regard, AS acts as a tool for ensuring communication between scientists and end-users of environmental information. Being effective both for the calculation of conservation priorities and in terms of potential impact assessment, AS represents a profitable tool to set up appropriate policies to achieve concrete GDE improvement results.

Supplementary Materials: The following materials are available online at http://www.mdpi.com/2073-4441/11/ 12/2574/s1, Table S1: PNECs calculated for 116 pollutants; Table S2: PNECs calculated for 474 species and 116 pollutants; Table S3: Input data for the calculation of ER and HHR in six sites of the River Sagittario (example of application); Table S4: Species abundances for the calculation of the GBC in six sites of the River Sagittario (example of application); Table S5: Species scores for the calculation of the GBC in six sites of the River Sagittario (example of application).

Author Contributions: Conceptualization, D.M.P.G., G.S., S.F., B.F., and T.D.L.; methodology, D.M.P.G., S.F., and B.F.; software, G.S., W.L., and F.B.; validation, D.M.P.G., S.F., B.F., and M.D.C.; analysis, D.M.P.G. and S.F.; data curation, D.M.P.G. and B.F.; writing — original draft preparation, D.M.P.G., G.S., S.F., T.D.L., and B.F.; writing-review and editing, D.M.P.G., T.D.L., B.F., S.F., and M.D.C.; visualization, M.D.C.; supervision, D.M.P.G.; project administration, B.F.; and funding acquisition, D.M.P.G.

Funding: This research was funded by the European Community (LIFE12 BIO/IT/000231 AQUALIFE).

Acknowledgments: The Stygobiology Laboratory (University of L'Aquila, Department of Life, Health and Environmental Sciences) is greatly acknowledged for the field activity and sorting of the invertebrates during the AQUALIFE project. 
Conflicts of Interest: The authors declare no conflict of interest.

\section{References}

1. Hatton, T.J.; Evans, R. Dependence of Ecosystems on Groundwater and Its Significance to Australia; CSIRO (Land and Water): Canberra, Australia, 1998.

2. Eamus, D.; Froend, R. Groundwater-dependent ecosystems: The where, what and why of GDEs. Aust. J. Bot. 2006, 54, 91-96. [CrossRef]

3. Gibert, J.; Deharveng, L. Subterranean ecosystems: A truncated functional biodiversity. Bioscience 2002, 52, 473-481. [CrossRef]

4. Humphreys, W.F. Aquifers: The ultimate groundwater-dependent ecosystems. Aust. J. Bot. 2006, 54, 115-132. [CrossRef]

5. Mammola, S.; Cardoso, P.; Culver, D.C.; Deharveng, L.; Ferreira, R.L.; Fiŝer, C.; Galassi, D.M.P.; Griebler, C.; Halse, S.; Humphreys, W.F.; et al. Scientists' Warning on the Conservation of Subterranean Ecosystems. Bioscience 2019, 69, 641-650. [CrossRef]

6. Ferreira, D.; Malard, F.; Dole-Olivier, M.-J.; Gibert, J. Obligate groundwater fauna of France: Diversity patterns and conservation implications. Biodivers. Conserv. 2007, 16, 567. [CrossRef]

7. Deharveng, L.; Stoch, F.; Gibert, J.; Bedos, A.; Galassi, D.; Zagmajster, M.; Brancelj, A.; Camacho, A.; Fiers, F.; Martin, P.; et al. Groundwater biodiversity in Europe. Freshw. Biol. 2009, 54, 709-726. [CrossRef]

8. Michel, G.; Malard, F.; Deharveng, L.; Di Lorenzo, T.; Sket, B.; De Broyer, C. Reserve selection for conserving groundwater biodiversity. Freshw. Biol. 2009, 54, 861-876. [CrossRef]

9. Galassi, D.M.P.; Fiasca, B.; Tosto, D. Patterns of Copepod diversity (Copepoda: Cyclopoida, Harpacticoida) in springs of central Italy: Implications for conservation issues. In Studies on Freshwater Copepoda: A Volume in Honour of Bernard Dussart; Brill: Buckinghamshire, UK, 2011; Volume 16, pp. 199-226.

10. European Commission. Technical Report on Groundwater Associated Aquatic Ecosystems; Technical Report No. 9; European Commission: Luxembourg, 2015.

11. Marmonier, P.; Maazouzi, C.; Baran, N.; Blanchet, S.; Ritter, A.; Saplairoles, M.; Dole-Olivier, M.J.; Galassi, D.M.P.; Eme, D.; Doledec, S.; et al. Ecology-based evaluation of groundwater ecosystems under intensive agriculture: A combination of community analysis and sentinel exposure. Sci. Total Environ. 2018, 613, 1353-1366. [CrossRef]

12. Jaffé, R.; Prous, X.; Zampaulo, R.; Giannini, T.C.; Imperatriz-Fonseca, V.L.; Maurity, C.; Oliveira, G.; Brandi, I.V.; Siqueira, J.O. Reconciling Mining with the Conservation of Cave Biodiversity: A Quantitative Baseline to Help Establish Conservation Priorities. PLoS ONE 2016, 11. [CrossRef]

13. EPA. EPA's Draft Report on the Environment Technical Document; EPA: Washington, DC, USA, 2003.

14. Tomlinson, M.; Boulton, A.J.; Hancock, P.J.; Cook, P.G. Deliberate omission or unfortunate oversight: Should stygofaunal surveys be included in routine groundwater monitoring programs? Hydrogeol. J. 2007, 15, 1317. [CrossRef]

15. Serov, P.; Kuginis, L.; Williams, J.P. Risk Assessment Guidelines for Groundwater Dependent Ecosystems, Volume 1-The Conceptual Framework; NSW Department of Primary Industries, Office of Water: Sydney, Australia, 2012.

16. Council of the European Communities. Directive 2000/60/EC of the European Parliament and the Council of 23 October 2000 establishing a framework for Community action in the field of water policy. Off. J. Eur. Commun. 2000, 327, 1-73.

17. Council of the European Communities. Directive 2006/118/EC of the European Parliament and of the Council of 12 December 2006 on the protection of groundwater against pollution and deterioration. Off. J. Eur. Union 2006, 372, 19-31.

18. Millennium Ecosystem Assessment, Ecosystems and Human Well-being: Synthesis; Island Press: Washington, DC, USA, 2005.

19. Kløve, B.; Ala-Aho, P.; Bertrand, G.; Boukalova, Z.; Erturk, A.; Goldscheider, N.; Ilmonen, J.; Karakaya, N.; Kupfersberger, H.; Kvaerner, J.; et al. Groundwater dependent ecosystems. Part I: Hydroecological status and trends. Environ. Sci. Policy 2011, 14, 770-781. [CrossRef]

20. Megdal, S.B.; Gerlak, A.K.; Varady, R.G.; Huang, L.Y. Groundwater Governance in the United States: Common Priorities and Challenges. Groundwater 2015, 53, 677-684. [CrossRef] [PubMed] 
21. Saccò, M.; Blyth, A.; Bateman, P.W.; Hua, Q.; Mazumder, D.; Nicole, W.; Humphreys, W.F.; Laini, A.; Griebler, C.; Grice, K. New light in the dark-A proposed multidisciplinary framework for studying functional ecology of groundwater fauna. Sci. Total Environ. 2019, 662, 963-977. [CrossRef]

22. Taylor, R.G.; Scanlon, B.; Doll, P.; Rodell, M.; van Beek, R.; Wada, Y.; Longuevergne, L.; Leblanc, M.; Famiglietti, J.S.; Edmunds, M.; et al. Ground water and climate change. Nat. Clim. Chang. 2013, 3, 322-329. [CrossRef]

23. Phyton Software Foundation (US). Available online: https://www.python.org/ (accessed on 3 October 2019).

24. Django Project. Available online: https://www.djangoproject.com (accessed on 3 October 2019).

25. Avramov, M.; Schmidt, S.I.; Griebler, C. A new bioassay for the ecotoxicological testing of VOCs on groundwater invertebrates and the effects of toluene on Niphargus inopinatus. Aquat. Toxicol. 2013, 130, 1-8. [CrossRef]

26. Di Lorenzo, T.; Borgoni, R.; Ambrosini, R.; Cifoni, M.; Galassi, D.M.P.; Petitta, M. Occurrence of volatile organic compounds in shallow alluvial aquifers of a Mediterranean region: Baseline scenario and ecological implications. Sci. Total Environ. 2015, 538, 712-723. [CrossRef]

27. Di Lorenzo, T.; Castano-Sanchez, A.; Di Marzio, W.D.; Garcia-Doncel, P.; Nozal Martinez, L.; Galassi, D.M.P.; Iepure, $\mathrm{S}$. The role of freshwater copepods in the environmental risk assessment of caffeine and propranolol mixtures in the surface water bodies of Spain. Chemosphere 2019, 220, 227-236. [CrossRef]

28. Di Lorenzo, T.; Di Marzio, W.D.; Fiasca, B.; Galassi, D.M.P.; Korbel, K.; Iepure, S.; Pereira, J.L.; Reboleira, A.; Schmidt, S.I.; Hose, G.C. Recommendations for ecotoxicity testing with stygobiotic species in the framework of groundwater environmental risk assessment. Sci. Total Environ. 2019, 681, 292-304. [CrossRef]

29. Calamari, D.; Vighi, M. A proposal to define quality objectives for aquatic life for mixtures of chemical-substances. Chemosphere 1992, 25, 531-542. [CrossRef]

30. Vighi, M.; Altenburger, R.; Arrhenius, Å.; Backhaus, T.; Bödeker, W.; Blanck, H.; Consolaro, F.; Faust, M.; Finizio, A.; Froehner, K.; et al. Water quality objectives for mixtures of toxic chemicals: Problems and perspectives. Ecotoxicol. Environ. Saf. 2003, 54, 139-150. [CrossRef]

31. Di Lorenzo, T.; Cifoni, M.; Fiasca, B.; Di Cioccio, A.; Galassi, D.M.P. Ecological risk assessment of pesticide mixtures in the alluvial aquifers of central Italy: Toward more realistic scenarios for risk mitigation. Sci. Total Environ. 2018, 644, 161-172. [CrossRef] [PubMed]

32. Pennington, D. Extrapolating ecotoxicological measures from small data sets. Ecotoxicol. Environ. Saf. 2003, 56, 238-250. [CrossRef]

33. Backhaus, T.; Faust, M. Predictive Environmental Risk Assessment of Chemical Mixtures: A Conceptual Framework. Environ. Sci. Technol. 2012, 46, 2564-2573. [CrossRef]

34. Gustavsson, M.; Kreuger, J.; Bundschuh, M.; Backhaus, T. Pesticide mixtures in the Swedish streams: Environmental risks, contributions of individual compounds and consequences of single-substance oriented risk mitigation. Sci. Total Environ. 2017, 598, 973-983. [CrossRef]

35. ECHA. Chapter, R.10: Characterisation of Dose [Concentration]-Response for Environment. Guidance for the Implementation of REACH-Guidance on Information Requirements and Chemical Safety Assessment; European Chemical Agency: Helskinki, Finland, 2008.

36. European Commission. Technical Guidance for Deriving Environmental Quality Standard; European Commission: Brussels, Belgium, 2018.

37. ECOTOX Database. Available online: https://cfpub.epa.gov/ecotox/ (accessed on 3 October 2019).

38. ECOSAR Software. Available online: http://www.epa.gov/oppt/newchems/tools/21ecosar.htm (accessed on 3 October 2019).

39. Galassi, D.M.P.; Fiasca, B.; Di Lorenzo, T.; Montanari, A.; Porfirio, S.; Fattorini, S. Groundwater biodiversity in a chemoautotrophic cave ecosystem: How geochemistry regulates microcrustacean community structure. Aquat. Ecol. 2017, 51, 75-90. [CrossRef]

40. Rinaldi, M.; Surian, N.; Comiti, F.; Bussettini, M. IDRAIM-Sistema di Valutazione Idromorfologica, Analisi E Monitoraggio dei Corsi d'acqua-Versione Aggiornata 2016; ISPRA: Rome, Italy, 2016.

41. Brunner, P.; Cook, P.G.; Simmons, C.T. Disconnected Surface Water and Groundwater: From Theory to Practice. Ground Water 2011, 49, 460-467. [CrossRef]

42. Siergieiev, D.; Ehlert, L.; Reimann, T.; Lundberg, A.; Liedl, R. Modelling hyporheic processes for regulated rivers under transient hydrological and hydrogeological conditions. Hydrol. Earth Syst. Sci. 2015, 19, 329-340. [CrossRef] 
43. Hancock, P.J. The response of hyporheic invertebrate communities to a large flood in the Hunter River, New South Wales. Hydrobiologia 2006, 568, 255-262. [CrossRef]

44. Arroita, M.; Flores, L.; Larranaga, A.; Martinez, A.; Martinez-Santos, M.; Pereda, O.; Ruiz-Romera, E.; Solagaistua, L.; Elosegi, A. Water abstraction impacts stream ecosystem functioning via wetted-channel contraction. Freshw. Biol. 2017, 62, 243-257. [CrossRef]

45. Liu, D.S.; Zhao, J.; Chen, X.B.; Li, Y.Y.; Weiyan, S.P.; Feng, M.M. Dynamic processes of hyporheic exchange and temperature distribution in the riparian zone in response to dam-induced water fluctuations. Geosci. J. 2018, 22, 465-475. [CrossRef]

46. Mathers, K.L.; Hill, M.J.; Wood, P.J. Benthic and hyporheic macroinvertebrate distribution within the heads and tails of riffles during baseflow conditions. Hydrobiologia 2017, 794, 17-30. [CrossRef]

47. Sawyer, A.H.; Cardenas, M.B.; Bomar, A.; Mackey, M. Impact of dam operations on hyporheic exchange in the riparian zone of a regulated river. Hydrol. Process. 2009, 23, 2129-2137. [CrossRef]

48. Boano, F.J.; Harvey, W.; Marion, A.; Packman, A.I.; Revelli, R.; Ridolfi, L.; Wörman, A. Hyporheic flow and transport processes: Mechanisms, models, and biogeochemical implications. Rev. Geophys. 2014, 52, 603-679. [CrossRef]

49. Magliozzi, C.; Grabowski, R.; Packman, A.; Krause, S. Scaling down hyporheic exchange flows: From catchments to reaches. Hydrol. Earth Syst. Sci. Discuss. 2017. [CrossRef]

50. European Commission. WFD Reporting Guidance 2016. Final Draft 6.0.6; European Commission: Brussels, Belgium, 2016.

51. Loheide, S.P.; Booth, E.G. Effects of changing channel morphology on vegetation, groundwater, and soil moisture regimes in groundwater-dependent ecosystems. Geomorphology 2011, 126, 364-376. [CrossRef]

52. Pacioglu, O.; Shaw, P.; Robertson, A. Patch scale response of hyporheic invertebrates to fine sediment removal in two chalk rivers. Fundam. Appl. Limnol. 2012, 181, 283-288. [CrossRef]

53. Jones, I.; Growns, I.; Arnold, A.; McCall, S.; Bowes, M. The effects of increased flow and fine sediment on hyporheic invertebrates and nutrients in stream mesocosms. Freshw. Biol. 2015, 60, 813-826. [CrossRef]

54. Pacioglu, O.; Robertson, A. The invertebrate community of the chalk stream hyporheic zone: Spatio-temporal distribution patterns. Knowl. Manag. Aquat. Ecosyst. 2017, 418, 10. [CrossRef]

55. Hancock, P.J. Human impacts on the stream-groundwater exchange zone. Environ. Manag. 2002, $29,763-781$. [CrossRef] [PubMed]

56. Merill, L.; Tonjes, D.J. A Review of the Hyporheic Zone, Stream Restoration, and Means to Enhance Denitrification. Crit. Rev. Sci. Technol. 2014, 44, 2337-2379. [CrossRef]

57. Wondzell, S.M. Effect of morphology and discharge on hyporheic exchange flows in two small streams in the Cascade Mountains of Oregon, USA. Hydrol. Process. 2006, 20, 267-287. [CrossRef]

58. Fumetti von, S.; Dmitrovic, D.; Pesic, V. The influence of flooding and river connectivity on macroinvertebrate assemblages in rheocrene springs along a third-order river. Fundam. Appl. Limnol. 2017, 190, 251-263. [CrossRef]

59. Pesic, V.; Dmitrovic, D.; Savic, A.; Milosevic, D.; Zawal, A.; Vukasinovic-Pesic, V.; Fumetti von, S. Application of macroinvertebrate multimetrics as a measure of the impact of anthropogenic modification of spring habitats. Aquat. Conserv. Mar. Freshw. Ecosyst. 2019, 29, 341-352. [CrossRef]

60. Salameh, E. Over-exploitation of groundwater resources and their environmental and socio-economic implications: The case of Jordan. Water Int. 2008, 33, 55-68. [CrossRef]

61. Tal, A.; Katz, D. Rehabilitating Israel's streams and rivers. Int. J. River Basin Manag. 2012, 10, $317-330$. [CrossRef]

62. Siwek, J.; Pociask-Karteczka, J. Springs in South-Central Poland-Changes and threats. Episodes 2017, 40, 38-46. [CrossRef]

63. Dwire, K.A.; Mellmann-Brown, S.; Gurrieri, J.T. Potential effects of climate change on riparian areas, wetlands, and groundwater-dependent ecosystems in the Blue Mountains, Oregon, USA. Clim. Serv. 2018, 10, 44-52. [CrossRef]

64. Sabater, F.; Butturini, A.; Mart, E.; Oz, I.; Romaní, A.; Wray, J.; Sabater, S. Effect of Riparian Vegetation Removal on Nutrient Retention in a Mediterranean Stream. J. N. Am. Benthol. Soc. 2000, 19, 609-620. [CrossRef]

65. Possingham, H.P.; Wilson, K.A. Biodiversity-Turning up the heat on hotspots. Nature 2005, 436, 919-920. [CrossRef] [PubMed] 
66. Funk, S.M.; Fa, J.E. Ecoregion Prioritization Suggests an Armoury Not a Silver Bullet for Conservation Planning. PLoS ONE 2010, 5, e8923. [CrossRef] [PubMed]

67. Cardoso, P.; Erwin, T.L.; Borges, P.A.V.; New, T.R. The seven impediments in invertebrate conservation and how to overcome them. Biol. Conserv. 2011, 144, 2647-2655. [CrossRef]

68. Fattorini, S. Use of insect rarity for biotope prioritisation: The tenebrionid beetles of the Central Apennines (Italy). J. Insect Conserv. 2010, 14, 367-378. [CrossRef]

69. Fattorini, S. Biotope prioritisation in the Central Apennines (Italy): Species rarity and cross-taxon congruence. Biodivers. Conserv. 2010, 19, 3413-3429. [CrossRef]

70. Fattorini, S.; Cardoso, P.; Rigal, F.; Borges, P.A.V. Use of Arthropod Rarity for Area Prioritisation: Insights from the Azorean Islands. PLoS ONE 2012, 7. [CrossRef] [PubMed]

71. Kattan, G.H. Rarity and vulnerability: The birds of the Cordillera Central of Colombia. Conserv. Biol. 1992, 6, 64-70. [CrossRef]

72. Rabinowitz, D. Seven forms of rarity. In The Biological Aspects of Rare Plant Conservation; Synge, H., Ed.; Sinauer Associates: Chichester, UK, 1981.

73. Rabinowitz, D.; Cairns, S.; Dillon, T. Seven forms of rarity and their frequency in the flora of the British Isles. In Conservation Biology: The Science of Scarcity and Diversity; Soulè, M.E., Ed.; British Ecological Society: London, UK, 1986; pp. 182-204.

74. Fattorini, S.; Fiasca, B.; Di Lorenzo, T.; Di Cicco, M.; Galassi, D.M.P. A new protocol for assessing the conservation priority of groundwater dependent ecosystems. Aquat. Conserv. Mar. Freshw. Ecosyst. submitted for publication.

75. Caschetto, M.; Galassi, D.M.P.; Petitta, M.; Aravena, R. Evaluation of the sources of nitrogen compounds and their influence on the biological communities in the hyporheic zone of the Sagittario River, Italy: An isotopic and biological approach. Ital. J. Geosci. 2017, 136, 145-156. [CrossRef]

76. Di Lorenzo, T.; Cannicci, S.; Spigoli, D.; Cifoni, M.; Baratti, M.; Galassi, D.M.P. Bioenergetic cost of living in polluted freshwater bodies: Respiration rates of the cyclopoid Eucyclops serrulatus under ammonia-N exposures. Fundam. Appl. Limnol. 2016, 188, 147-156. [CrossRef]

77. Di Lorenzo, T.; Cifoni, M.; Lombardo, P.; Fiasca, B.; Galassi, D.M.P. Ammonium threshold values for groundwater quality in the EU may not protect groundwater fauna: Evidence from an alluvial aquifer in Italy. Hydrobiologia 2015, 743, 139-150. [CrossRef]

78. Scharf, B.; Brunke, M. The recolonization of the river Elbe with benthic and hyporheic Ostracoda (Crustacea) after the reunion of Germany in 1989. Int. Rev. Hydrobiol. 2013, 98. [CrossRef]

79. Hahn, H.J. The GW-Fauna-Index: A first approach to a quantitative ecological assessment of groundwater habitats. Limnologica 2006, 36, 119-137. [CrossRef]

80. Fillinger, L.; Hug, K.; Trimbach, A.M.; Wang, H.; Kellermann, C.; Meyer, A.; Bendinger, B.; Griebler, C. The D-A-(C) index: A practical approach towards the microbiological-ecological monitoring of groundwater ecosystems. Water Res. 2019, 163, 114902. [CrossRef] [PubMed]

81. Korbel, K.; Hose, G.C. The weighted groundwater health index: Improving the monitoring and management of groundwater resources. Ecol. Indic. 2017, 75, 164-181. [CrossRef]

82. Korbel, K.L.; Hose, G.C. A tiered framework for assessing groundwater ecosystem health. Hydrobiologia 2011, 661, 329-349. [CrossRef]

(C) 2019 by the authors. Licensee MDPI, Basel, Switzerland. This article is an open access article distributed under the terms and conditions of the Creative Commons Attribution (CC BY) license (http://creativecommons.org/licenses/by/4.0/). 